\title{
Ventilatory strategy during liver transplantation: implications for near-infrared spectroscopy-determined frontal lobe oxygenation
}

\author{
Henrik Sørensen ${ }^{1 *}$, Hilary P. Grocott ${ }^{2}$, Mads Niemann ${ }^{1}$, Allan Rasmussen ${ }^{3}$, Jens G. Hillingsø ${ }^{3}$, \\ Hans J. Frederiksen ${ }^{1}$ and Niels H. Secher ${ }^{1}$ \\ ${ }^{1}$ Department of Anesthesia, Rigshospitalet, University of Copenhagen, Copenhagen, Denmark \\ ${ }^{2}$ Department of Anesthesia and Perioperative Medicine, St. Boniface Hospital, University of Manitoba, Winnipeg, MB, Canada \\ ${ }^{3}$ Department of Surgery and Transplantation, Rigshospitalet, University of Copenhagen, Copenhagen, Denmark
}

Edited by:

Patrice Brassard, Laval University,

Canada

\section{Reviewed by:}

Stephane Perrey, Montpellier I

University, France

Phil Neil Ainslie, University of British

Columbia, Canada

${ }^{*}$ Correspondence:

Henrik Sorensen, Department of Anesthesia, Rigshospitalet 2041,

Blegdamsvej 9, DK-2100

Copenhagen, Denmark

e-mail: hs770@hotmail.com
Background: As measured by near infrared spectroscopy (NIRS), cerebral oxygenation $\left(\mathrm{S}_{\mathrm{C}} \mathrm{O}_{2}\right)$ may be reduced by hyperventilation in the anhepatic phase of liver transplantation surgery (LTX). Conversely, the brain may be subjected to hyperperfusion during reperfusion of the grafted liver. We investigated the relationship between $\mathrm{S}_{\mathrm{C}} \mathrm{O}_{2}$ and end-tidal $\mathrm{CO}_{2}$ tension $\left(\mathrm{EtCO}_{2}\right)$ during the various phases of LTX.

Methods: In this retrospective study, 49 patients undergoing LTx were studied. Forehead $\mathrm{S}_{\mathrm{c}} \mathrm{O}_{2}, \mathrm{EtCO}_{2}$, minute ventilation (VE), and hemodynamic variables were recorded from the beginning of surgery through to the anhepatic and reperfusion phases during LTX.

Results: In the anhepatic phase, $\mathrm{S}_{\mathrm{C}} \mathrm{O}_{2}$ was reduced by $4.3 \%(95 \%$ confidence interval: $2.5-6.0 \% ; P<0.0001), \mathrm{EtCO}_{2}$ by $0.3 \mathrm{kPa}(0.2-0.4 \mathrm{kPa} ; P<0.0001)$, and $\mathrm{VE}$ by $0.4 \mathrm{~L} / \mathrm{min}$ (0.1-0.7 L/min; $P=0.0018)$. Conversely, during reperfusion of the donated liver, $\mathrm{S}_{\mathrm{c}} \mathrm{O}_{2}$ increased by $5.5 \%(3.8-7.3 \%), \mathrm{EtCO}_{2}$ by $0.7 \mathrm{kPa}(0.5-0.8 \mathrm{kPa})$, and $\mathrm{VE}$ by $0.6 \mathrm{~L} / \mathrm{min}$ (0.3-0.9 L/min; all $P<0.0001)$. Changes in $\mathrm{S}_{\mathrm{c}} \mathrm{O}_{2}$ were correlated to those in $\mathrm{EtCO}_{2}$ (Pearson $r=0.74 ; P<0.0001$ ).

Conclusion: During $L T x$, changes in $\mathrm{S}_{\mathrm{c}} \mathrm{O}_{2}$ are closely correlated to those of $\mathrm{EtCO}_{2}$. Thus, this retrospective analysis suggests that attention to maintain a targeted $\mathrm{EtCO}_{2}$ would result in a more stable $\mathrm{S}_{\mathrm{c}} \mathrm{O}_{2}$ during the operation.

Keywords: cerebral oxygenation, cerebral oximetry, end-tidal carbon dioxide, liver transplantation, monitoring, ventilation

\section{INTRODUCTION}

Autoregulation ensures that cerebral blood flow (CBF) is sufficient to meet the metabolic requirements of the brain, but may be challenged by a low arterial pressure, hypoxia and/or hypocapnia (Kety and Schmidt, 1948; Lassen, 1959). Maintaining mean arterial pressure (MAP) within the cerebral autoregulatory range during surgery has been suggested to result in improved patient outcome (Ono et al., 2013). An evolving strategy for control of the circulation during surgery is to maintain cerebral oxygenation $\left(\mathrm{S}_{\mathrm{c}} \mathrm{O}_{2}\right)$, a real-time surrogate for $\mathrm{CBF}$ measured using near infrared spectroscopy (NIRS). $\mathrm{S}_{\mathrm{c}} \mathrm{O}_{2}$ not only has the ability to identify whether patients demonstrate intact cerebral autoregulation, but also determines its lower limit threshold (Nissen et al., 2009).

Impaired cerebral autoregulation (Larsen et al., 1995), cerebral hyperemia, and increased intracranial pressure (Aggarwal et al., 1994) are all associated with end-stage liver disease and may predispose to either ischemic or hyperemic cerebral injury. Cerebral perfusion and thereby $\mathrm{S}_{\mathrm{c}} \mathrm{O}_{2}$, is challenged by the hemodynamic events that can occur during liver transplantation (LTx) (Adams et al., 1987; Larsen et al., 1999; Pere et al., 2000; Van Mook et al., 2005; Nissen et al., 2010; Zheng et al., 2012). In the hepatic dissection phase, there is a risk for hemorrhage. In the anhepatic phase inadequate venous return to the heart and a low arterial carbon dioxide tension $\left(\mathrm{P}_{\mathrm{a}} \mathrm{CO}_{2}\right)$ can occur. This contrasts with the reperfusion phase where increases in $\mathrm{P}_{\mathrm{a}} \mathrm{CO}_{2}$ may occur (Pere et al., 2000; Panzera et al., 2006). With clamping of the inferior vena cava (IVC), cardiac output (CO) is reduced by as much as $50 \%$, and this can result in compromised perfusion to vital organs including the brain (Pere et al., 2000). Thus, to facilitate hemodynamic stability and to optimize organ perfusion, veno-venous bypass may be utilized (Shaw et al., 1985). Alternatively, venous return to the heart may be assisted by only partially clamping the IVC (so-called piggyback technique) (Panzera et al., 2006). However, even with the piggyback technique, $\mathrm{S}_{\mathrm{c}} \mathrm{O}_{2}$ is likely to decrease by about $15 \%$ (Panzera et al., 2006) increasing the risk of cerebral ischemia (Al-Rawi and Kirkpatrick, 2006).

In the anhepatic phase of LTx, the systemic metabolic rate is reduced by $\sim 30 \%$ and there is therefore a reduced need for minute ventilation (VE) in order to preserve $\mathrm{CBF}$ and $\mathrm{S}_{\mathrm{c}} \mathrm{O}_{2}$. Conversely, with reperfusion of the grafted liver, metabolism is restored and the brain may be subjected to hyperperfusion due to enhanced $\mathrm{CO}_{2}$ and/or liberation of vasodilating substances (Ejlersen et al., 1994; Skak et al., 1997) that could lead to brain 
edema, hemorrhage and even death (Van Mook et al., 2005). $\mathrm{S}_{\mathrm{c}} \mathrm{O}_{2}$ follows changes in $\mathrm{CBF}$ with hyper- and hypo-capnia (Rasmussen et al., 2007) and therefore to maintain $\mathrm{S}_{\mathrm{c}} \mathrm{O}_{2}$ during the operation potentially minimizes incidence of post-operative neurological complications (Madsen and Secher, 2000; Pere et al., 2000; Zheng et al., 2012).

In this retrospective observational study, we reviewed $\mathrm{S}_{\mathrm{c}} \mathrm{O}_{2}$, end-tidal $\mathrm{CO}_{2}$ tension $\left(\mathrm{EtCO}_{2}\right)$, and VE for LTx patients and hypothesized that $\mathrm{S}_{\mathrm{c}} \mathrm{O}_{2}$ would decrease in the anhepatic phase of the operation and increase again with reperfusion of the grafted liver. We considered that the data would provide an indication as to what extent VE should be adjusted to maintain $\mathrm{S}_{\mathrm{c}} \mathrm{O}_{2}$ and potentially contribute to brain protection during LTx.

\section{MATERIALS AND METHODS}

Data were collected retrospectively for patients undergoing LTx at Rigshospitalet (Copenhagen) from 1997 to 2001. The study was performed in accordance with guidelines provided by The National Committee on Health Research and approved by the Local Ethical Committee (H-2-2014-FSP27) who waived the need for patient consent.

The liver transplantation technique involved clamping of the IVC with lower body venous return supported by a veno-venous bypass from the left femoral vein to one or two arm veins (Rasmussen et al., 1994). Reperfusion of the grafted liver was established by opening the IVC above the hepatic vein, followed by the IVC below the hepatic vein, and lastly the hepatic artery. Reported hemodynamic variables include heart rate (HR) and femoral MAP measured via an arterial catheter (Becton Dickinson and Company, New Jersey, NY, USA) cardiac output (CO) by thermodilution (7.5F; Baxter, Uden, Holland), thoracic electrical impedance index (THI) $(n=30)$ (TI; Caspersen and Nielsen, Copenhagen, Denmark) as an indication of the central blood volume (Cai et al., 2000), and $\mathrm{S}_{\mathrm{c}} \mathrm{O}_{2}$ (Invos 3100 Cerebral Oximeter, Somanetics, Troy, MI, USA) along with VE and $\mathrm{EtCO}_{2}$. $\mathrm{P}_{\mathrm{a}} \mathrm{CO}_{2}$ was not continuously monitored, however, it was assumed that $\mathrm{EtCO}_{2}$ reflects changes in $\mathrm{P}_{\mathrm{a}} \mathrm{CO}_{2}$ as expressed by the ratio between $\mathrm{CO}_{2}$ and the alveolar ventilation. All values were noted every $10 \mathrm{~min}$ as recorded in the anesthetic chart. Hematocrit was monitored (ABL 700 Radiometer, Copenhagen) and any administration of packed red blood cells and plasma was performed through a rapid infusion system (Haemonetics, Braintree, MA, USA) to maintain a hematocrit of $30 \%$.

Data from the last $60 \mathrm{~min}$ of the dissection phase, first and last $30 \mathrm{~min}$ of the anhepatic phase, and the first $40 \mathrm{~min}$ of the reperfusion phase of the operation were included in the analysis. Hemodynamic changes from dissection to early anhepatic phase were calculated as the difference between an average over $60 \mathrm{~min}$ in the dissection phase and $30 \mathrm{~min}$ in the early anhepatic phase. Changes from late anhepatic to reperfusion phase were identified as the difference in average from the last $30 \mathrm{~min}$ of the anhepatic phase, and the first 20 min of the reperfusion phase.

Distribution of data including variance and probability plots were assessed independently for each patient and the whole population using Proc Univariate in SAS 9.2 (SAS Institute, Cary NC, USA). All variables exhibited normal distribution, however,
$\mathrm{CO}$ and THI were skewed to the right. Thus, we performed a logarithmic transformation $\left(\log _{10}\right)$ on CO and THI-data and relative changes are reported as $\log (\mathrm{x})-\log (\mathrm{y})=\log (\mathrm{x} / \mathrm{y})$ (Bland and Altman, 1996a). In Figure 1, CO and THI are presented as geometric means $\pm 95 \%$ confidence interval (Bland and Altman, 1996b). We applied an analysis of variance followed by a TukeyKramer post-hoc test to evaluate changes between conditions and a $P$-value $<0.05$ was considered as statistically significant. Association between $\mathrm{S}_{\mathrm{c}} \mathrm{O}_{2}, \mathrm{VE}$, and $\mathrm{EtCO}_{2}$ was evaluated by Pearson's correlation. Since $\mathrm{S}_{c} \mathrm{O}_{2}$ has been reported to decrease with increasing plasma bilirubin (Madsen et al., 2000; Song et al., 2011) that relation was also evaluated with Spearman rank order correlation.

\section{RESULTS}

Forty nine patients, [ 21 women, 28 men, $53 \pm 10$ (mean \pm SD) years] were admitted for LTx. Twenty six patients had cirrhosis, 5 primary biliary cirrhosis, 4 primary sclerosing cholangitis, 3 acute liver failure, 3 hepatocellular carcinoma, and the remaining 8 patients had other liver diseases. The duration of surgery was $368 \mathrm{~min}$ (range; 240-675), representing $141 \mathrm{~min}$ (60-465) for the dissection phase of the operation, $83 \mathrm{~min}(50-250)$ for the anhepatic phase, and $145 \mathrm{~min}$ (70-230) for completion of the operation.

\section{ANHEPATIC PHASE}

From the initial dissection to the anhepatic phase of the operation, $\mathrm{S}_{\mathrm{c}} \mathrm{O}_{2}$ and $\mathrm{EtCO}_{2}$ decreased by $4.3 \%$ [ $(95 \%$ confidence intervals: $2.5-6.0 \%)$ and by $0.3 \mathrm{kPa}(0.2-0.4 \mathrm{kPa}$; both $P<0.0001)$ ] as VE was reduced by $0.4 \mathrm{~L} / \mathrm{min}(0.1-0.7 \mathrm{~L} / \mathrm{min} ; P=0.0018)$. HR, MAP, and THI remained stable (Figure 1). CO was reduced by $15 \%(6-24 \% ; P=0.0003)$.

Changes in $\mathrm{S}_{\mathrm{c}} \mathrm{O}_{2}$ was correlated to those in $\mathrm{EtCO}_{2}$ (Pearson $r=0.74 ; P<0.0001)$, however, no correlation between $\mathrm{S}_{\mathrm{c}} \mathrm{O}_{2}$ and VE was observed (Pearson $r=0.06 ; P=0.7$ ) (Figure 2). In 11 patients, $\mathrm{S}_{\mathrm{c}} \mathrm{O}_{2}$ was reduced by more than $15 \%$. We observed an inverse relationship between $\mathrm{S}_{\mathrm{c}} \mathrm{O}_{2}$ with plasma bilirubin (Spearman $r=-0.49 ; P=0.008$ ) ranging from 9 to $565 \mu \mathrm{mol} / \mathrm{L}$ $(n=28)$.

\section{REPERFUSION PHASE}

During reperfusion of the grafted liver, $\mathrm{S}_{\mathrm{c}} \mathrm{O}_{2}$ and $\mathrm{EtCO}_{2}$ increased $5.5 \%(3.8-7.3 \%)$ and $0.7 \mathrm{kPa}(0.5-0.8 \mathrm{kPa} ; P<0.0001)$ as $\mathrm{VE}$ was increased by $0.6 \mathrm{~L} / \mathrm{min}(-0.5-3.1 \mathrm{~L} / \mathrm{min}$; all $P<0.0001)$ (Figure 1). No changes were observed in HR and THI, but CO increased by $90 \%$ (71-110\%; $P<0.0001)$. Conversely, MAP decreased by $5 \mathrm{mmHg}(1-9 \mathrm{mmHg} ; P=0.007)$. No significant correlation between $\mathrm{S}_{\mathrm{c}} \mathrm{O}_{2}$ and VE was identify (Pearson $r=-$ $0.18 ; P=0.21)$ (Figure 2), but 13 patients $\mathrm{S}_{\mathrm{c}} \mathrm{O}_{2}$ increased $>15 \%$ compared to the late anhepatic phase.

\section{DISCUSSION}

In this retrospective study of measurements during LTx in 49 patients, cerebral oxygenation $\left(\mathrm{S}_{\mathrm{c}} \mathrm{O}_{2}\right)$, as determined by NIRS, was shown to decrease in the anhepatic phase of the operation and to increase during reperfusion of the grafted liver. Changes in $\mathrm{S}_{\mathrm{c}} \mathrm{O}_{2}$ were directly related to the end-tidal $\mathrm{CO}_{2}$ tension. Therefore, a ventilatory strategy directed to a maintain 

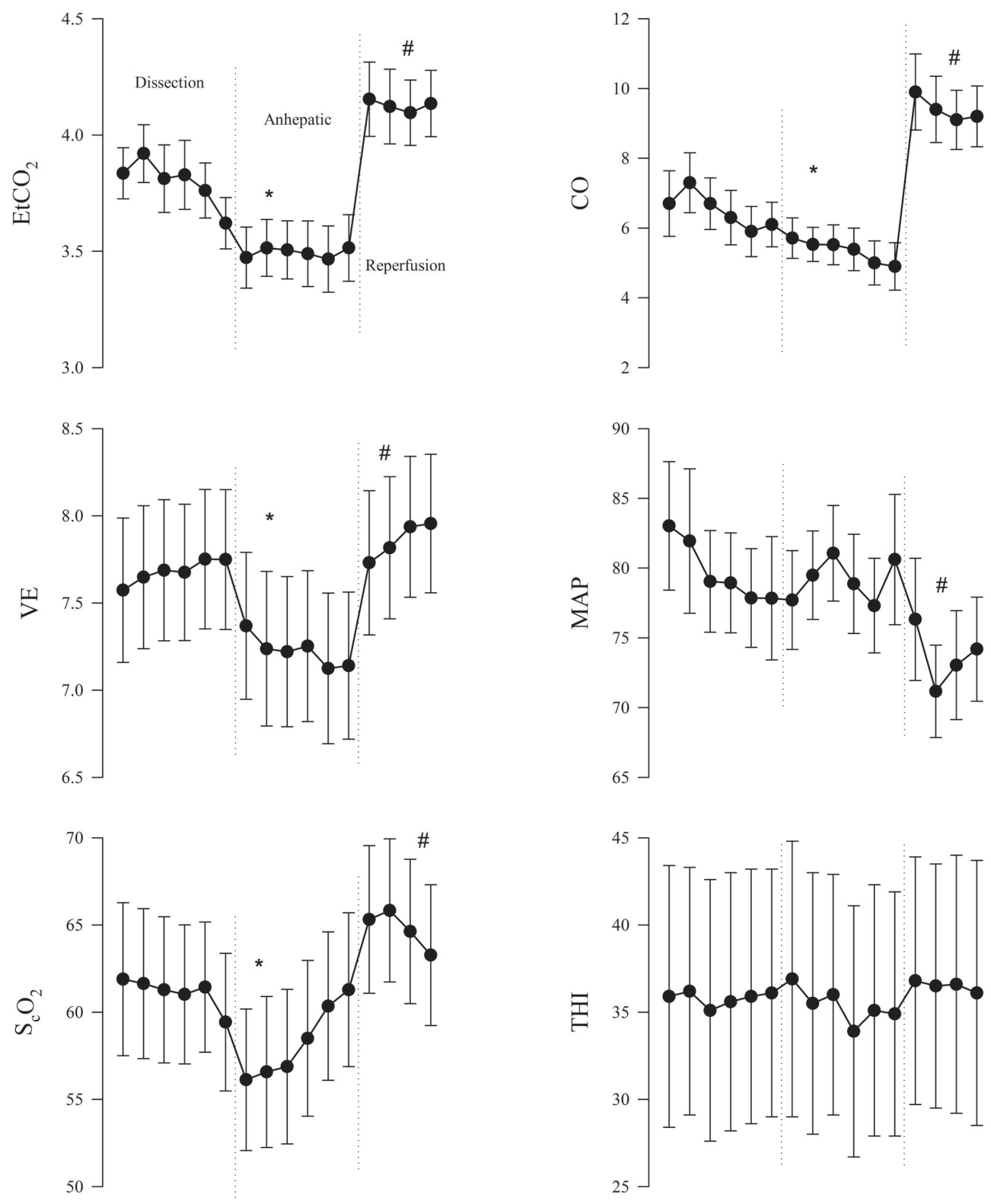

FIGURE 1 | Mean ( $\pm 95 \%$ confidence interval) for 10th $\mathrm{min}$ in the dissection, anhepatic and reperfusion phases of liver transplantation surgery for end-tidal $\mathrm{CO}_{2}$ tension $\left(\mathrm{EtCO}_{2}\right)$; ventilation (VE); near infrared spectroscopy-determined frontal lobe oxygenation $\left(\mathrm{S}_{\mathrm{c}} \mathrm{O}_{2}\right)$; cardiac

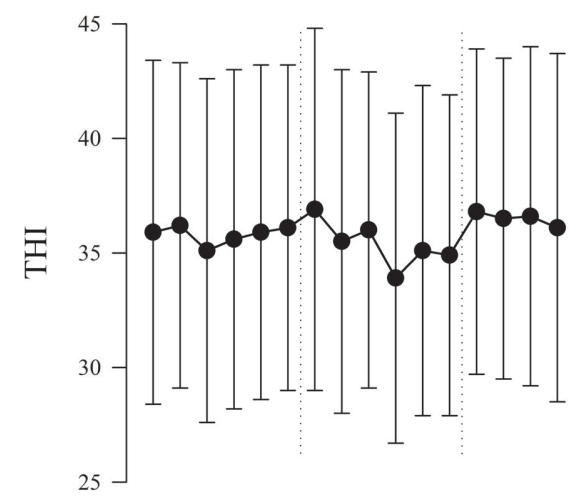

output (CO); mean arterial pressure (MAP); and thoracic electrical impedance index (THI). $\mathrm{CO}$ and $\mathrm{THI}$ reported as geometric means. ${ }^{*} P<0.05$ compared to the dissection phase of the operation. ${ }^{\#} P<0.05$ compared to the anhepatic phase.

$\mathrm{EtCO}_{2}$ could ensure stability of $\mathrm{S}_{\mathrm{c}} \mathrm{O}_{2}$ during the operation and may, at least potentially, minimize the incidence of post-operative seizures, confusion, and stroke (Madsen and Secher, 2000; Pere et al., 2000; Zheng et al., 2012). Despite bilirubin absorption of infrared light resulting in a low $\mathrm{S}_{\mathrm{c}} \mathrm{O}_{2}$, NIRS detected changes in cerebral oxygenation even in patients who were significantly jaundiced (Madsen et al., 2000).

Patients with liver disease are susceptible to alterations in MAP that can frequently result in pressure below the limits of cerebral autoregulation and then may lead to cerebral ischemia.
Cerebral oxygenation might further be aggravated by increases in intracranial pressure that reduce cerebral perfusion pressure according to the Monro-Kellie doctrine (Larsen and Wendon, 2008). Thus, it seems to be an advantage if handling of the circulation during LTx involves continuous monitoring of the brain circulation to reduce adverse neurological outcome. NIRS represents a real-time, though indirect, monitor of $\mathrm{CBF}$ and indicates its autoregulatory capacity (Nissen et al., 2009; Zheng et al., 2012). In this cohort of LTx patients, $\mathrm{S}_{\mathrm{c}} \mathrm{O}_{2}$ was reduced by $4.3 \%$ (2.5-6.0\%) with IVC clamping (Figure 1), which is likely induced 


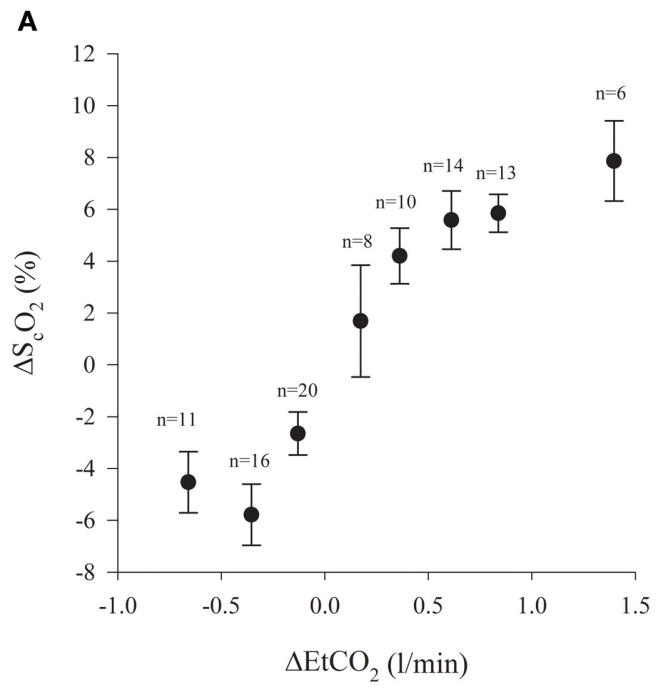

FIGURE 2 | (A) Frontal lobe oxygenation $\left(\mathrm{S}_{\mathrm{C}} \mathrm{O}_{2}\right)$ and end-tidal $\mathrm{CO} 2$ tension $\left(\mathrm{EtCO}_{2}\right)$ in the anhepatic and reperfusion phases of liver transplantation surgery ( $\%$ changes from baseline; \pm s.e.m.) (Pearson $r=0.74 ; P<0.0001$ ). Number of subjects indicated. (B) Changes
B

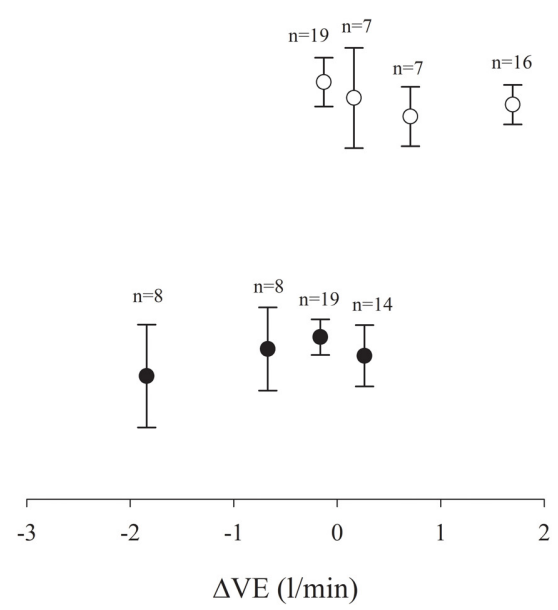

from baseline ( \pm s.e.m.) for $\mathrm{S}_{\mathrm{C}} \mathrm{O}_{2}$ and ventilation (VE). Black symbols: anhepatic phase (Pearson $r=0.06 ; P=0.7$ ). Open symbols: reperfusion phase (Pearson $r=-0.18 ; P=0.21$ ). Number of subjects is indicated. by hyperventilation as indicated by a reduction in $\mathrm{EtCO}_{2}$ by $0.3 \mathrm{kPa}$, albeit $\mathrm{VE}$ was diminished by $0.4 \mathrm{l} / \mathrm{min}$. Thus, with the central blood volume maintained as indicated by THI (Cai et al., 2000), a ventilatory strategy guided by $\mathrm{EtCO}_{2}$ may avoid cerebral ischemia in the anhepatic phase (Pott et al., 1995), e.g., by keeping $\mathrm{EtCO}_{2}$ between 4.7 and $6.0 \mathrm{kPa}$, arterial $\mathrm{CO}_{2}, \mathrm{CBF}$, and $\mathrm{S}_{\mathrm{c}} \mathrm{O}_{2}$ were maintained (Pott et al., 1995; Zheng et al., 2012). In contrast, no ventilatory adjustment in the anhepathic phase of the operation has been reported to lead to pronounced reductions in $\mathrm{P}_{\mathrm{a}} \mathrm{CO}_{2}$, and yet maintained $\mathrm{CBF}$ as indicated by transcranial Doppler (Pere et al., 2000). In that study (Pere et al., 2000), cardiac preload was not supported by a venous-venous bypass, while we registered an $15 \%$ reduction in CO when the shunt was established. Although we cannot rule out that this reduction in $\mathrm{CO}$ may affect $\mathrm{CBF}$ and $\mathrm{S}_{\mathrm{c}} \mathrm{O}_{2}$, we find it more likely that changes in $\mathrm{S}_{\mathrm{c}} \mathrm{O}_{2}$ relate to alterations in $\mathrm{EtCO}_{2}$ than to the reduction in $\mathrm{CO}$ with the hierarchy of blood flow in the anhepatic phase (Figure 2) (Rhee et al., 2012; Ono et al., 2013; Mahal et al., 2014). In $22 \%$ of the patients, $\mathrm{S}_{\mathrm{c}} \mathrm{O}_{2}$ was reduced by $>15 \%$ (relative to the value in the dissection phase) thus lowering the threshold for cerebral ischemia (Al-Rawi and Kirkpatrick, 2006). Similar significant cerebral deoxygenation is reported in up to $50 \%$ of patients undergoing LTx (Plachky et al., 2004), and also seen with the use of the piggy-back technique (Panzera et al., 2006).

Postoperative biomarkers of brain damage include neuronspecific enolase and S-100 $\beta$ and they may increase three-fold in patients who demonstrate cerebral deoxygenation (Plachky et al., 2004). S-100 $\beta$ levels are high in patients who develope post-operative cognitive dysfunction (POCD) (Linstedt et al., 2002) and cerebral deoxygenation ( $>15 \%$ relative to baseline) is related to POCD and longer hospital stay (Casati et al., 2005; Ballard et al., 2012; Colak et al., 2014). Moreover, inherent to prolonged cerebral deoxygenation, confusion, somnolence and transient hemiparesis manifest post-operatively (Madsen and Secher, 2000) or permanent neurological damage develops (Philips et al., 1998). Also in patients with acute liver failure, cerebral infarction after LTx can led to long-term hospital care, however, perioperative cerebral oxygenation was not reported for that patient (Pere et al., 2000). In general, patients with encephalopathy have been reported with a $15 \%$ higher $\mathrm{S}_{\mathrm{c}} \mathrm{O}_{2}$ (Panzera et al., 2006), may be as a result of cerebral hyperemia because of lack of cerebral autoregulation (Ejlersen et al., 1994). However, similar reductions of $\sim 30 \%$ relative to the pre-operative $\mathrm{S}_{\mathrm{c}} \mathrm{O}_{2}$ were seen with IVC clamping in patients with and without encephalopathy (Panzera et al., 2006).

When the transplanted liver is reperfused, the brain can be subjected to hyperemia due to enhanced $\mathrm{CO}_{2}$ reactivity and/or liberation of vasodilating substances (Ejlersen et al., 1994) as we demonstrated by the $0.7 \mathrm{kPa}$ increase in $\mathrm{EtCO}_{2}$ and if untreated can have adverse effects and affect even mortality (Skak et al., 1997). With impaired cerebral autoregulation, the risk of hyperperfusion is even larger due to missing cerebral vasoconstriction in response a $90 \%$ increase in $\mathrm{CO}$ and be aggravated by the vasodilatory effect of $\mathrm{CO}_{2}$ (Figure 1). Accordingly, $\mathrm{S}_{\mathrm{c}} \mathrm{O}_{2}$ may guide to what extent $\mathrm{VE}$ should be increased in order to protect the brain. We observed an increase in $\mathrm{S}_{\mathrm{c}} \mathrm{O}_{2}$ by $5.5 \%(3.8-7.3 \%)$ during reperfusion although $\mathrm{VE}$ was increased by $0.6 \mathrm{l} / \mathrm{min}$. We, therefore, suggest a more meticulous control of $\mathrm{VE}$ is in need, as guided by $\mathrm{EtCO}_{2}$, until the end of LTx (Nissen et al., 2010). Although $\mathrm{EtCO}_{2}$ was kept within 4.6-6.0 kPa (Pott et al., 1995; Zheng et al., 2012) or VE increased by 15\% (Pere et al., 2000), CBF becomes elevated (by more than $80 \%$ in some patients) with reperfusion of the liver, which emphasizes that attempts to maintain $\mathrm{EtCO}_{2}$ toward the end of the operation could attenuate 
cerebral hyperperfusion (Pott et al., 1995; Philips et al., 1998; Zheng et al., 2012).

The $\mathrm{P}_{\mathrm{a}} \mathrm{CO}_{2}$ relates to hydrogen ion concentration and is a potent modulator of cerebrovascular resistance and, thus, $\mathrm{CBF}$ (Lassen, 1959). Hypercapnia leads to cerebral vasodilation while the opposite occurs with hypocapnia through a serial of endogenous mediators (Eriksson et al., 1983). In healthy humans, CBF increases $2-8 \%$ per $\mathrm{mmHg} \mathrm{CO}_{2}$ as determined by Fick's principle (Kety and Schmidt, 1946) or transcranial Doppler (Madsen and Secher, 1999), however, $\mathrm{CO}_{2}$-reactivity has not yet been describe for NIRS despite $\mathrm{S}_{\mathrm{c}} \mathrm{O}_{2}$ does follow CBF induced by hypercapnia and hypocapnia (Rasmussen et al., 2007). As evaluated by ${ }^{133}$ Xenon clearance in patients undergoing LTx, CBF increases by $25 \%$ and may be more than can be explained by the increase in $\mathrm{P}_{\mathrm{a}} \mathrm{CO}_{2}$ (Larsen et al., 1999). Increasing $\mathrm{P}_{\mathrm{a}} \mathrm{CO}_{2}$ may mitigate the $\mathrm{CO}_{2}$-reactivity because of near-maximal cerebral vasodilatation or may be attributable to other vasodilating substances interfering with the effect of $\mathrm{CO}_{2}$ on the cerebral vasculature (Philips et al., 1998).

As this was a retrospective study, we did not evaluate neurological outcome. In related studies, neurological complications range from mild seizures to hemorrhage and stroke after LTx (Adams et al., 1987; Stein et al., 1992; Madsen and Secher, 2000; Pere et al., 2000; Zheng et al., 2012) and cerebral hemorrhage and anoxic-ischemic lesions are common at brain autopsy after LTx (Ferreiro et al., 1992). However, the evidence for improved neurological outcome by maintaining $\mathrm{S}_{\mathrm{c}} \mathrm{O}_{2}$ during LTx remains sparse, although improved outcome is seen in cardiac (Slater et al., 2009; Ono et al., 2013; Colak et al., 2014; Harilall et al., 2014), abdominal (Casati et al., 2005), and orthopedic surgery (Ballard et al., 2012). An observational cohort study is underway investigating the relationship between perioperative desaturation during hepatic surgery or LTx and adverse postoperative events and length of ICU stay, but optimization of $\mathrm{S}_{\mathrm{c}} \mathrm{O}_{2}$ in the anhepatic and reperfusion phase is not included (clinicaltrials.gov: NCT01458262). Although the adequacy of cerebral autoregulation and oxygenation can be monitored in the operating room, impaired $\mathrm{CBF}$ regulation may persist into the early postoperative phase (Larsen et al., 1999), but no study describes the efficacy of maintaining cerebral monitoring in the ICU after LTx (Ejlersen et al., 1994; Van Mook et al., 2005).

From this retrospective study, we conclude that despite adjustments of VE in the anhepatic and reperfusion phases of LTx, $\mathrm{S}_{\mathrm{c}} \mathrm{O}_{2}$ changes occur that have the potential to expose patients to cerebral ischemia and/or hyperemia. We suggest that a ventilatory strategy guided by $\mathrm{EtCO}_{2}$ would keep $\mathrm{S}_{\mathrm{c}} \mathrm{O}_{2}$ more stable during LTx.

\section{AUTHOR CONTRIBUTIONS}

All authors contributed equally to the design, data analysis and interpretation, drafting the manuscript and critical revision. All authors approved the final version before submission.

\section{ACKNOWLEDGMENTS}

Assistance with the article: We thank Carol A. Cooke, MLIS (Neil John Maclean Health Sciences Library) for developing the literature search strategies and John McVagh, Study Coordinator,
Department of Anesthesia, University of Manitoba, for invaluable help and encouragement. Financial support and sponsorship: The author (Henrik Sørensen) received a grant from Dansk Medicinsk Selskab i København to visit Department of Anesthesia \& Perioperative Medicine, St. Boniface Hospital, University of Manitoba, Winnipeg, Canada.

\section{REFERENCES}

Adams, D. H., Ponsford, S., Gunson, B., Boon, A., Honigsberger, L., Williams, A., et al. (1987). Neurological complications following liver transplantation. Lancet 1, 949-951. doi: 10.1016/S0140-6736(87)90294-7

Aggarwal, S., Kramer, D., Yonas, H., Obrist, W., Kang, Y., Martin, M., et al. (1994). Cerebral hemodynamic and metabolic changes in fulminant hepatic failure: a retrospective study. Hepatology 19, 80-87. doi: 10.1002/hep.1840190114

Al-Rawi, P. G., and Kirkpatrick, P. J. (2006). Tissue oxygen index: thresholds for cerebral ischemia using near-infrared spectroscopy. Stroke 37, 2720-2725. doi: 10.1161/01.STR.0000244807.99073.ae

Ballard, C., Jones, E., Gauge, N., Aarsland, D., Nilsen, O. B., Saxby, B. K., et al. (2012). Optimised anaesthesia to reduce post operative cognitive decline (POCD) in older patients undergoing elective surgery, a randomised controlled trial. PLoS ONE 7:e37410. doi: 10.1371/journal.pone.0037410

Bland, J. M., and Altman, D. G. (1996a). Statistics notes. Logarithms. BMJ 312, 700 doi: 10.1136/bmj.312.7032.700

Bland, J. M., and Altman, D. G. (1996b). Transformations, means, and confidence intervals. BMJ 312, 1079. doi: 10.1136/bmj.312.7038.1079

Cai, Y., Holm, S., Jenstrup, M., Stromstad, M., Eigtved, A., Warberg, J., et al. (2000). Electrical admittance for filling of the heart during lower body negative pressure in humans. J. Appl. Physiol. (1985) 89, 1569-1576.

Casati, A., Fanelli, G., Pietropaoli, P., Proietti, R., Tufano, R., Danelli, G., et al. (2005). Continuous monitoring of cerebral oxygen saturation in elderly patients undergoing major abdominal surgery minimizes brain exposure to potential hypoxia. Anesth. Analg. 101, 740-747. doi: 10.1213/01.ane.0000166974.96219.cd

Colak, Z., Borojevic, M., Bogovic, A., Ivancan, V., Biocina, B., and MajericKogler, V. (2014). Influence of intraoperative cerebral oximetry monitoring on neurocognitive function after coronary artery bypass surgery: a randomized, prospective study. Eur. J. Cardiothorac. Surg. doi: 10.1093/ejcts/ezu193. [Epub ahead of print].

Ejlersen, E., Larsen, F. S., Pott, F., Gyrtrup, H. J., Kirkegaard, P., and Secher, N. H. (1994). Hepatectomy corrects cerebral hyperperfusion in fulminant hepatic failure. Transplant. Proc. 26, 1794-1795.

Eriksson, S., Hagenfeldt, L., Law, D., Patrono, C., Pinca, E., and Wennmalm, A. (1983). Effect of prostaglandin synthesis inhibitors on basal and carbon dioxide stimulated cerebral blood flow in man. Acta Physiol. Scand. 117, 203-211. doi: 10.1111/j.1748-1716.1983.tb07198.x

Ferreiro, J. A., Robert, M. A., Townsend, J., and Vinters, H. V. (1992). Neuropathologic findings after liver transplantation. Acta Neuropathol. 84, 1-14. doi: 10.1007/BF00427209

Harilall, Y., Adam, J. K., Biccard, B. M., and Reddi, A. (2014). The effect of optimising cerebral tissue oxygen saturation on markers of neurological injury during coronary artery bypass graft surgery. Heart Lung Circ. 23, 68-74. doi: 10.1016/j.hlc.2013.07.002

Kety, S. S., and Schmidt, C. F. (1946). The effects of active and passive hyperventilation on cerebral blood flow, cerebral oxygen consumption, cardiac output, and blood pressure of normal young men. J. Clin. Invest. 25, 107-119. doi: 10.1172/JCI101680

Kety, S. S., and Schmidt, C. F. (1948). The effects of altered arterial tensions of carbon dioxide and oxygen on cerebral blood floow and cerebral oxygen consumption of normal young men. J. Clin. Invest. 27, 484-492. doi: 10.1172/JCI101995

Larsen, F. S., Ejlersen, E., Hansen, B. A., Knudsen, G. M., Tygstrup, N., and Secher, N. H. (1995). Functional loss of cerebral blood flow autoregulation in patients with fulminant hepatic failure. J. Hepatol. 23, 212-217. doi: 10.1016/01688278(95)80338-6

Larsen, F. S., Ejlersen, E., Strauss, G., Rasmussen, A., Kirkegaard, P., Hansen, B. A., et al. (1999). Cerebrovascular metabolic autoregulation is impaired during liver transplantation. Transplantation 68, 1472-1476. doi: 10.1097/00007890199911270-00007 
Larsen, F. S., and Wendon, J. (2008). Prevention and management of brain edema in patients with acute liver failure. Liver Transpl. 14(Suppl. 2), S90-S96. doi: 10.1002/lt.21643

Lassen, N. A. (1959). Cerebral blood flow and oxygen consumption in man. Physiol. Rev. 39, 183-238.

Linstedt, U., Meyer, O., Kropp, P., Berkau, A., Tapp, E., and Zenz, M. (2002). Serum concentration of S-100 protein in assessment of cognitive dysfunction after general anesthesia in different types of surgery. Acta Anaesthesiol. Scand. 46, 384-389. doi: 10.1034/j.1399-6576.2002.460409.x

Madsen, P. L., and Secher, N. H. (1999). Near-infrared oximetry of the brain. Prog. Neurobiol. 58, 541-560. doi: 10.1016/S0301-0082(98)00093-8

Madsen, P. L., and Secher, N. H. (2000). Postoperative confusion preceded by decreased frontal lobe haemoglobin oxygen saturation. Anaesth. Intensive Care 28, 308-310.

Madsen, P. L., Skak, C., Rasmussen, A., and Secher, N. H. (2000). Interference of cerebral near-infrared oximetry in patients with icterus. Anesth. Analg. 90, 489-493. doi: 10.1213/00000539-200002000-00046

Mahal, I., Davie, S. N., and Grocott, H. P. (2014). Cerebral oximetry and thoracic surgery. Curr. Opin. Anaesthesiol. 27, 21-27. doi: 10.1097/ACO.0000000000000027

Nissen, P., Frederiksen, H. J., and Secher, N. H. (2010). Intraoperative hemodynamic monitoring during liver transplantation: goals and devices. Minerva Gastroenterol. Dietol. 56, 261-277.

Nissen, P., Pacino, H., Frederiksen, H. J., Novovic, S., and Secher, N. H. (2009). Near-infrared spectroscopy for evaluation of cerebral autoregulation during orthotopic liver transplantation. Neurocrit. Care 11, 235-241. doi: 10.1007/s12028-009-9226-8

Ono, M., Arnaoutakis, G. J., Fine, D. M., Brady, K., Easley, R. B., Zheng, Y., et al. (2013). Blood pressure excursions below the cerebral autoregulation threshold during cardiac surgery are associated with acute kidney injury. Crit. Care Med. 41, 464-471. doi: 10.1097/CCM.0b013e31826ab3al

Panzera, P., Greco, L., Carravetta, G., Gentile, A., Catalano, G., Cicco, G., et al. (2006). Alteration of brain oxygenation during "piggy back" liver transplantation. Adv. Exp. Med. Biol. 578, 269-275. doi: 10.1007/0-387-29540-2_43

Pere, P., Hockerstedt, K., Isoniemi, H., and Lindgren, L. (2000). Cerebral blood flow and oxygenation in liver transplantation for acute or chronic hepatic disease without venovenous bypass. Liver Transpl. 6, 471-479. doi: 10.1053/jlts.2000.8186

Philips, B. J., Armstrong, I. R., Pollock, A., and Lee, A. (1998). Cerebral blood flow and metabolism in patients with chronic liver disease undergoing orthotopic liver transplantation. Hepatology 27, 369-376. doi: 10.1002/hep.510270209

Plachky, J., Hofer, S., Volkmann, M., Martin, E., Bardenheuer, H. J., and Weigand, M. A. (2004). Regional cerebral oxygen saturation is a sensitive marker of cerebral hypoperfusion during orthotopic liver transplantation. Anesth. Analg. 99, 344-349, doi: 10.1213/01.ANE.0000124032.31843.61

Pott, F., Larsen, F. S., Ejlersen, E., Linkis, P., Jorgensen, L. G., and Secher, N. H. (1995). Cerebral perfusion during human liver transplantation. Clin. Physiol. 15, 119-130. doi: 10.1111/j.1475-097X.1995.tb00436.x

Rasmussen, L. S., Ejlersen, E., Hjortrup, A., Kirkegaard, P., and Secher, N. H. (1994). Veno-venous bypass during human liver transplantation. Transplant. Proc. 26, 1791.
Rasmussen, P., Dawson, E. A., Nybo, L., Van Lieshout, J. J., Secher, N. H., and Gjedde, A. (2007). Capillary-oxygenation-level-dependent near-infrared spectrometry in frontal lobe of humans. J. Cereb. Blood Flow Metab. 27, 1082-1093. doi: 10.1038/sj.jcbfm.9600416

Rhee, C. J., Kibler, K. K., Easley, R. B., Andropoulos, D. B., Czosnyka, M., Smielewski, P., et al. (2012). Renovascular reactivity measured by nearinfrared spectroscopy. J. Appl. Physiol. 113, 307-314. doi: 10.1152/japplphysiol.00024.2012

Shaw, B. W. Jr., Martin, D. J., Marquez, J. M., Kang, Y. G., Bugbee, A. C. Jr., Iwatsuki, S., et al. (1985). Advantages of venous bypass during orthotopic transplantation of the liver. Semin. Liver Dis. 5, 344-348. doi: 10.1055/s-2008-1040631

Skak, C., Rasmussen, A., Kirkegaard, P., and Secher, N. H. (1997). Cerebral oxygen saturation and blood flow during liver transplantation. Anesth. Analg. 84, 730-733.

Slater, J. P., Guarino, T., Stack, J., Vinod, K., Bustami, R. T., Brown, J. M. 3rd., et al. (2009). Cerebral oxygen desaturation predicts cognitive decline and longer hospital stay after cardiac surgery. Ann. Thorac. Surg. 87, 36-44. discussion: 44-45. doi: 10.1016/j.athoracsur.2008.08.070

Song, J. G., Jeong, S. M., Shin, W. J., Jun, I. G., Shin, K., Huh, I. Y., et al. (2011) Laboratory variables associated with low near-infrared cerebral oxygen saturation in icteric patients before liver transplantation surgery. Anesth. Analg. 112, 1347-1352. doi: 10.1213/ANE.0b013e318214b2b0

Stein, D. P., Lederman, R. J., Vogt, D. P., Carey, W. D., and Broughan, T. A. (1992). Neurological complications following liver transplantation. Ann. Neurol. 31, 644-649. doi: 10.1002/ana.410310612

Van Mook, W. N., Rennenberg, R. J., Schurink, G. W., Van Oostenbrugge, R. J., Mess, W. H., Hofman, P. A., et al. (2005). Cerebral hyperperfusion syndrome. Lancet Neurol. 4, 877-888. doi: 10.1016/S1474-4422(05)70251-9

Zheng, Y., Villamayor, A. J., Merritt, W., Pustavoitau, A., Latif, A., Bhambhani, R., et al. (2012). Continuous cerebral blood flow autoregulation monitoring in patients undergoing liver transplantation. Neurocrit. Care 17, 77-84. doi: $10.1007 / \mathrm{s} 12028-012-9721-1$

Conflict of Interest Statement: The authors declare that the research was conducted in the absence of any commercial or financial relationships that could be construed as a potential conflict of interest.

Received: 31 May 2014; accepted: 04 August 2014; published online: 25 August 2014. Citation: Sørensen H, Grocott HP, Niemann M, Rasmussen A, Hillingsø JG, Frederiksen HJ and Secher NH (2014) Ventilatory strategy during liver transplantation: implications for near-infrared spectroscopy-determined frontal lobe oxygenation. Front. Physiol. 5:321. doi: 10.3389/fphys.2014.00321

This article was submitted to Integrative Physiology, a section of the journal Frontiers in Physiology.

Copyright (c) 2014 Sørensen, Grocott, Niemann, Rasmussen, Hillingsø, Frederiksen and Secher. This is an open-access article distributed under the terms of the Creative Commons Attribution License (CC BY). The use, distribution or reproduction in other forums is permitted, provided the original author(s) or licensor are credited and that the original publication in this journal is cited, in accordance with accepted academic practice. No use, distribution or reproduction is permitted which does not comply with these terms. 